\title{
SEFT MENURUNKAN TEKANAN DARAH PADA LANSIA HIPERTENSI
}

\author{
${ }^{1}$ Gita Nur fitri, ${ }^{2}$ Lilis Lismayanti, \& ${ }^{3}$ Nina Pamela Sari \\ ${ }^{1}$ Alumni Keperawatan UMTAS, ${ }^{2,3}$ Dosen Keperawatan UMTAS
}

\begin{abstract}
Abstrak
Tujuan penelitian untuk mengetahui pengaruh terapi SEFT terhadap penurunan tekanan darah pada lansia di wilayah kerja UPTD Puskesmas Tawang Kota Tasikmalaya. Jenis penelitian analitik dengan pendekatan quasi eksperimenpre-test dan post test two group design untuk menganalisis hasil eksperimen yang menggunakan intervensi sebelum dan sesudah pada dua kelompok. Populasi semua pasien lansia yang berumur antara 60-74 tahun yang mengalami hipertensi esensial di Wilayah Kerja UPTD Puskesmas Tawang Kota Tasikmalaya sebanyak 48 orang dengan jumlah sampel 30 orang, 15 orang lansia laki-laki dan 15 orang lansia perempuan. Alat pengumpul data dengan sphygmomanometer digital dan buku panduan terapi SEFT. Analisa data terdiri dari univariat dan bivariat dengan menggunakan uji T dependen dan independen. Hasil penelitian tidak ada perbedaan tekanan sistolik sebelum dan sesudah terapi SEFT pada kelompok lansia laki-laki dan kelompok lansia perempuan dengan $p$-value 0,385 namun ada perbedaan pada tekanan diastolik sesudah terapi SEFT pada kelompok lansia lakilaki dan kelompok lansia perempuan dengan $p$-value 0,035. Untuk mendapatkan hasil yang lebih optimal, disarankan bagi responden yang memiliki faktor risiko sebaiknya dilakukan terapi SEFT pada faktor risikonya terlebih dahulu sebelum melakukan SEFT pada hipertensinya.
\end{abstract}

Kata kunci : Hipertensi, Lansia, SEFT

\begin{abstract}
The aim of research is to determine the effect of SEFT therapy to the decrease of the blood pressure in the elderly, particularly in the region of Tawang UPTD Puskesmas Tasikmalaya. The method employed was analytic quasi-experimental with pre-test and post-test two group design to analyze the results of experiments after the intervention. The population of all elderly patients between the ages of 60-74 years old who have essential hypertension in the Work Area UPTD Tawang Puskesmas Tasikmalaya are people. Total sample are 15 elderly men and women. Data were collection through digital sphygmomanometer and guide books SEFT therapy. Data analysis consisted of univariate and bivariate using dependent and independent $T$ test. The results of the study showed that there was no difference in systolic blood pressure before and after therapy SEFT on a group of elderly men and a group of elderly women with $p$ value 0.385 , but no difference in diastolic blood pressure after treatment SEFT on a group of elderly men and a group of elderly women with $p$ value 0.035 . To obtain the optimum result, particulary to the participants with risk factor, they had better implement SEFT earlier before it has been done to its hypertention.
\end{abstract}

Keywords : Elderly, Hypertension, SEFT

\section{PENDAHULUAN}

Hasil pendataan Riskesdas (Riset Kesehatan Dasar) 2013 terjadi peningkatan prevalensi hipertensi berdasarkan wawancara dari $7,6 \%$ pada tahun 2007 menjadi 9,5\% pada tahun 2013.SEFT merupakan teknik terapi psikologi yang lahir dari perkembangan berbagai teknik pengobatan dengan menggunakan sistem energi tubuh.SEFTmerupakan metoda baru dalam melakukan EFT yang dinilai lebih efektif dan lebih powerfull (Zainudin,2009). Tujuan penelitian ini untuk mengetahui pengaruhterapi SEFT terhadap penurunan tekanan darah pada lansia hipertensi di Puskesmas Tawang Kota Tasikmalaya. 


\section{METODE PENELITIAN}

Jenis penelitian menggunakan pendekatan quasi eksperimen dengan jenis experimental pre-test dan post test two group design yang menggunakan intervensi sebelum dan sesudah pada dua kelompok. Populasinya adalah lansia berumur 60-74 tahun yang hipertensi sebanyak 48 orang.Sampelnya adalah lanjut usia dengan hipertensi sebanyak 30 orang, 15 laki-laki dan 15 perempuan.

Prosedur penelitian yang dilakukan adalah menyeleksi pasien sesuai kriteria inklusi dan dibagi berdasarkan jenis kelamin, memberikan penjelasan penelitian dan menawarkan menjadi responden penelitian, menanyakan biodata pasien terkait nama, umur, dan riwayat hipertensi. Mengukur tekanan darah dan mencatatnya. Melakukan SEFT dan mengukur ulang tekanan darah serta mencatatnya kembali.

Data penelitian yang didapatkan berdistribusi normal dan kedua kelompok data independen. Variabel yang dihubungkan berbentuk numerik dan kategorik. Uji T independen dibagi dua jenis yaitu uji $T$ independen varian sama bila $p$ value (sig) levene test $>0,05$ dan uji $\mathrm{T}$ independen varian berbeda bila $p$ value (sig) levene test $\leq 0,05$.

\section{HASIL PENELITIAN}

1. Perbedaan tekanan sistolik lansia laki-laki sebelum dan sesudah terapi SEFT di Puskesmas Tawang Kota Tasikmalaya

Tabel 1. Perbedaan rata-rata tekanan sistolik lansia laki-laki sebelum dan sesudah Terapi SEFT di Puskesmas Tawang Kota Tasikmalaya

\begin{tabular}{ccccc}
\hline $\begin{array}{c}\text { Variabel } \\
\text { Tekanan Darah }\end{array}$ & $\begin{array}{c}\text { Rata-rata } \\
\text { Tekanan Darah }\end{array}$ & $\begin{array}{c}\text { Cl } \\
95 \%\end{array}$ & SD & $\rho$-value \\
\cline { 1 - 2 } $\begin{array}{c}\text { Tekanan Sistolik } \\
\text { Sebelum Terapi SEFT }\end{array}$ & $169,73 \mathrm{mmHg}$ & $1,322-11,878$ & 12,680 & 0,018 \\
\cline { 1 - 2 } $\begin{array}{c}\text { Tekanan Sistolik } \\
\text { Sesudah Terapi SEFT }\end{array}$ & $163,13 \mathrm{mmHg}$ & & 15,679 & \\
\hline
\end{tabular}

Hasil uji paired-tdiperoleh nilai $\rho=0,018(\rho<0,05)$, berarti secara statistik ada perbedaan yang signifikan rata-rata tekanan sistolik lansia laki-laki sebelum dan sesudah SEFT.

2. Perbedaan tekanan diastolik lansia laki-laki sebelum dan sesudah terapi SEFT di Puskesmas Tawang Kota Tasikmalaya

Tabel 2. Perbedaan rata-rata tekanan diastolik lansia laki-laki sebelum dan sesudah Terapi SEFT di Puskesmas Tawang Kota Tasikmalaya

\begin{tabular}{ccccc}
\hline $\begin{array}{c}\text { Variabel } \\
\text { Tekanan Darah }\end{array}$ & $\begin{array}{c}\text { Rata-rata } \\
\text { Tekanan Darah }\end{array}$ & $\begin{array}{c}\mathrm{Cl} \\
95 \%\end{array}$ & SD & $\rho$-value \\
\cline { 1 - 2 } $\begin{array}{c}\text { Tekanan Diastolik } \\
\text { Sebelum Terapi SEFT }\end{array}$ & $102,40 \mathrm{mmHg}$ & $2,877-8,457$ & 7,405 & 0,001 \\
\cline { 1 - 2 } $\begin{array}{c}\text { Tekanan Diastolik } \\
\text { Sesudah Terapi SEFT }\end{array}$ & $96,73 \mathrm{mmHg}$ & & 9,916 & \\
\hline
\end{tabular}

Hasil uji paired-tdiperoleh nilai $\rho=0,001 \quad(\rho<0,05)$, berarti secara statistik ada perbedaan yang signifikan rata-rata tekanan diastolik lansia laki-laki sebelum dan sesudah SEFT. 
3. Perbedaan tekanan sistolik lansia perempuan sebelum dan sesudah terapi SEFT di Puskesmas Tawang Kota Tasikmalaya

Tabel 3. Perbedaan rata-rata tekanan sistolik lansia perempuan sebelum dan sesudah Terapi SEFT di Puskesmas Tawang Kota Tasikmalaya

\begin{tabular}{|c|c|c|c|c|}
\hline $\begin{array}{c}\text { Variabel } \\
\text { Tekanan Darah }\end{array}$ & $\begin{array}{c}\text { Rata-rata } \\
\text { Tekanan Darah }\end{array}$ & $\begin{array}{c}\mathrm{Cl} \\
95 \%\end{array}$ & SD & $\rho$-value \\
\hline $\begin{array}{c}\text { Tekanan Sistolik } \\
\text { Sebelum Terapi SEFT }\end{array}$ & $168 \mathrm{mmHg}$ & \multirow[t]{2}{*}{$5,603-13,064$} & 13,207 & \multirow[t]{2}{*}{0,000} \\
\hline $\begin{array}{c}\text { Tekanan Sistolik } \\
\text { Sesudah Terapi SEFT }\end{array}$ & $158,67 \mathrm{mmHg}$ & & 11,776 & \\
\hline
\end{tabular}

Hasil uji paired-tdiperoleh nilai $\rho=0,000(\rho<0,05)$, berarti secara statistik ada perbedaan yang signifikan rata-rata tekanan sistolik lansia perempuan sebelum dan sesudah SEFT.

4. Perbedaan tekanan diastolik lansia perempuan sebelum dan sesudah terapi SEFT di Puskesmas Tawang Kota Tasikmalaya

Tabel 4. Perbedaan rata-rata tekanan diastolik lansia perempuan sebelum dan sesudah Terapi SEFTdi Puskesmas Tawang Kota Tasikmalaya

\begin{tabular}{ccccc}
\hline $\begin{array}{c}\text { Variabel } \\
\text { Tekanan Darah }\end{array}$ & $\begin{array}{c}\text { Rata-rata } \\
\text { Tekanan Darah }\end{array}$ & $\begin{array}{c}\text { Cl } \\
95 \%\end{array}$ & SD & $\rho$-value \\
\cline { 1 - 2 } $\begin{array}{c}\text { Tekanan Diastolik } \\
\text { Sebelum Terapi SEFT }\end{array}$ & $97,73 \mathrm{mmHg}$ & $5,001-11,132$ & 8,031 & 0,000 \\
$\begin{array}{cccc}\text { Tekanan Diastolik } \\
\text { Sesudah Terapi SEFT }\end{array}$ & $89,67 \mathrm{mmHg}$ & & 8,508 & \\
\hline
\end{tabular}

Hasil uji paired-tdiperoleh nilai $\rho=0,000(\rho<0,05)$, berarti secara statistik ada perbedaan yang signifikan rata-rata tekanan sistolik lansia perempuan sebelum dan sesudah SEFT.

5. Perbedaan tekanan sistolik lansia laki-laki dan lansia perempuan sebelum terapi SEFT di wilayah kerja UPTD Puskesmas Tawang Kota Tasikmalaya

Tabel 5. Perbedaan rata-rata tekanan sistolik lansia laki-laki dan perempuan sebelum terapi SEFT di Puskesmas Tawang Kota Tasikmalaya

\begin{tabular}{cccccc}
\hline Variabel & $\begin{array}{c}\text { Rata-rata } \\
\text { Tekanan Darah }\end{array}$ & $\begin{array}{c}\mathrm{Cl} \\
95 \%\end{array}$ & SD & $\rho$-value \\
\cline { 1 - 2 } $\begin{array}{c}\text { Tekanan Sistolik } \\
\text { Lansia Laki-laki }\end{array}$ & $169,73 \mathrm{mmHg}$ & $7,950-11,417$ & 12,680 & 0,717 \\
\cline { 1 - 2 } $\begin{array}{c}\text { Tekanan Sistolik } \\
\text { Lansia Perempuan }\end{array}$ & $168,00 \mathrm{mmHg}$ & & 13,207 & \\
\hline
\end{tabular}

Hasil uji $T$-test diperoleh nilai $\rho=0,717$, hal ini menunjukkan bahwa nilai $\rho>0,05$, berarti secara statistik tidak ada perbedaan yang signifikan rata-rata tekanan sistolik antara lansia laki-laki dan perempuan sebelum terapi SEFT. 
6. Perbedaan tekanan sistolik lansia laki-laki dan lansia perempuan sesudah terapi SEFT di Puskesmas Tawang Kota Tasikmalaya

Tabel 6. Perbedaan rata-rata tekanan sistolik lansia laki-laki dan perempuan sesudah terapi SEFT di Puskesmas Tawang Kota Tasikmalaya

\begin{tabular}{cccccc}
\hline Variabel & $\begin{array}{c}\text { Rata-rata } \\
\text { Tekanan Darah }\end{array}$ & $\begin{array}{c}\mathrm{Cl} \\
\text { Te }\end{array}$ & SD & $\rho$-value \\
\cline { 1 - 2 } $\begin{array}{c}\text { Tekanan Sistolik } \\
\text { Lansia Laki-laki }\end{array}$ & $163,13 \mathrm{mmHg}$ & \multirow{2}{*}{$5,904-14,838$} & 15,679 & 0,385 \\
\cline { 1 - 2 } $\begin{array}{c}\text { Tekanan Sistolik } \\
\text { Lansia Perempuan }\end{array}$ & $158,67 \mathrm{mmHg}$ & & 11,776 & \\
\hline
\end{tabular}

Hal ini menunjukkan bahwa nilai $\rho>0,05$, berarti secara statistik tidak ada perbedaan yang signifikan rata-rata tekanan sistolik antara lansia laki-laki dan perempuan sesudah SEFT.

7. Perbedaan tekanan diastolik lansia laki-laki dan lansia perempuan sebelum terapi SEFT di Puskesmas Tawang Kota Tasikmalaya

Tabel 7. Perbedaan rata-rata tekanan diastolik lansia laki-laki dan perempuan sebelum terapi SEFT di Puskesmas Tawang Kota Tasikmalaya

\begin{tabular}{cccccc}
\hline Variabel & $\begin{array}{c}\text { Rata-rata } \\
\text { Tekanan Darah }\end{array}$ & $\begin{array}{c}\mathrm{Cl} \\
95 \%\end{array}$ & SD & $\rho$-value \\
\cline { 1 - 2 } $\begin{array}{c}\text { Tekanan Diastolik } \\
\text { Lansia Laki-laki }\end{array}$ & $102,40 \mathrm{mmHg}$ & $1,111-10,444$ & 7,405 & 0,109 \\
\cline { 1 - 2 } $\begin{array}{c}\text { Tekanan Diastolik } \\
\text { Lansia Perempuan }\end{array}$ & $97,73 \mathrm{mmHg}$ & & 8,031 & \\
\hline
\end{tabular}

Hasil uji $T$-test diperoleh nilai $\rho=0,109$, hal ini menunjukkan bahwa nilai $\rho>0,05$, berarti secara statistik tidak ada perbedaan yang signifikan rata-rata tekanan diastolik antara lansia laki-laki dan perempuan sebelum terapi SEFT.

8. Perbedaan tekanan diastolik lansia laki-laki dan perempuan sesudah terapi SEFT di Puskesmas Tawang Kota Tasikmalaya

Tabel 8. Perbedaan rata-rata tekanan diatolik lansia laki-laki dan perempuan sesudah terapi SEFT di Puskesmas Tawang Kota Tasikmalaya

\begin{tabular}{cccccc}
\hline Variabel & $\begin{array}{c}\text { Rata-rata } \\
\text { Tekanan Darah }\end{array}$ & $\begin{array}{c}\mathrm{Cl} \\
95 \%\end{array}$ & SD & $\rho$-value \\
\cline { 1 - 2 } $\begin{array}{c}\text { Tekanan DiastolikLansia } \\
\text { Laki-laki }\end{array}$ & $96,73 \mathrm{mmHg}$ & & $549-13,585$ & 8,916 & 0,035 \\
\cline { 1 - 2 } $\begin{array}{c}\text { Tekanan DiastolikLansia } \\
\text { Perempuan }\end{array}$ & $89,67 \mathrm{mmHg}$ & & 8,508 & \\
\hline
\end{tabular}

Hasil uji $T$-test diperoleh nilai $\rho=0,035$, hal ini menunjukkan bahwa nilai $\rho<0,05$, berarti secara statistik ada perbedaan yang signifikan rata-rata tekanan diastolik antara lansia laki-laki dan perempuan sesudah mendapatkan terapi SEFT. 
PEMBAHASAN

Perbedaan tekanan sistolik lansia laki-laki sebelum dan sesudah terapi SEFT di Puskesmas Tawang Kota Tasikmalaya

Penyebab tingginya tekanan sistolik pada kelompok lansia laki-laki dikarenakan adanya faktor risiko lain seperti merokok dan kurang aktivitas fisik yang menyebabkan peredaran darah menjadi kurang baik. Beberapa penelitian menunjukkan pendekatan nonfarmakologis, termasuk penurunan berat badan, pembatasan alkohol, natrium dan tembakau, latihan dan relaksasi merupakan intervensi wajib yang harus dilakukan pada setiap terapi antihipertensi (Brunner \& Suddarth, 2013; Muttaqin, 2009).SEFT dapat membantu para responden untuk menetralisir gangguan yang dialaminnya (Zainudin, 2014).Pelaksanaan terapi SEFT pada lansia laki-laki memerlukan waktu untuk memahamkannya. Ada sebagian yang masih belum menunjukkan kekhusyuan selama pelaksanaan SEFT, sehingga penurunan tekanan darah sistolik sesudah $S E F T$ tidak sebesar penurunan pada lansia perempuan.

\section{Perbedaan tekanan diastolik lansia laki-laki sebelum dan sesudah terapiSEFT di Puskesmas Tawang Kota Tasikmalaya}

Keausan arteriosklerosis dari arteriarteri utama terutama aorta, dan akibat dari berkurangnya kelenturan menjadi masalah bagi lansia. Menurut Wolff, 2008; Stanley, Mickey,2012; Maryam, et al.2008; Tamher, Noorkasiani,2008, pengerasan dan semakin bertambah kakunya arteri-arteri ini menjadikan arteri dan aorta itu kehilangan daya penyesuaian diri. Dinding yang kini tidak elastis, tidak dapat lagi mengubah darah yang keluar dari jantung menjadi aliran yang lancar.Hasilnya adalah gelombang denyut yang tidak terputus dengan lembah yang dalam (diastolik).Terapi SEFT bisa menyebabkan darah yang keluar dari jantung menjadi lancar sehingga menyebabkan tekanan darah diastolik pada lansia laki-laki menurun dari sebelum dilakukan terapi SEFT karena dapatmenetralisir rasa sakit fisik yang dialami oleh responden.

Perbedaan tekanan sistolik lansia
perempuan sebelum dan sesudah terapi
SEFT di Puskesmas Tawang Kota
Tasikmalaya
SEFT merupakan sebuah metode
yang menggunakan dasar sistem energi tubuh dalam menghilangkan masalahmasalah fisik maupun emosi secara cepat (Zainudin, 2009). Menurut Hastuti dalam Oktafiani, 2010 menyatakan bahwa wanita lansia mengalami kecemasan yang meningkat.Hal ini terjadi karena banyak faktor misalnya kehilangan pasangan, penurunan seksualitas dan lain sebagainya.Pelaksanaan terapi SEFT pada lansia perempuan lebih mudah mengikuti instruksi dan menghayati terapi.Bahkan sebagian responden secara terbuka menyampaikan masalahnya.Sehingga setelah dilakukan terapi SEFT, lansia perempuan menjadi lebih rileks dan perasaan menjadi lebih tenang.Hal tersebut menjadi sebab adanya perbedaan yang cukup besar pada penurunan tekanan sistolik sesudah dilakukan terapi SEFT.

Perbedaan tekanan diastolik lansia perempuan sebelum dan sesudah terapi SEFT di Puskesmas Tawang Kota Tasikmalaya

Peneliti Pratita dan Oris, 2011; Teti dan Subiyanto, 2013; Debi dan Susanti, 2015; Rofacky, 2015, juga melakukan penelitian serupa serta menunjukkan adanya penurunan tekanan diastolik sesudah dilakukan terapi SEFT. Teknik SEFT pada tahap set up,tune in maupun tapping yang mengajarkan individu untuk dapat ikhlas dan pasrah kepada Tuhan dalam menghadapi setiap persoalan. SEFT memberikan pemaknaan yang bersifat spiritualitas pada terhadap persoalan yang dihadapinya.Do'a mempunyai dampak yang positif terhadap kondisi psikologis.Wachholtz \& Sambaamorthi (2011); Lewis \& Barnes (2008); Wachholtz \& Sambaamorthi (2011) dalam Hidayati (2011), menyatakan hal yang 
senada bahwa terdapat korelasi antara do'a dengan kualitas mental seseorang.

\section{Perbedaan tekanan sistolik lansia laki-laki dan lansia perempuan sebelum terapi SEFT di wilayah Puskesmas Tawang Kota Tasikmalaya}

Kondisi gerontologis menyebabkan perubahan struktural dan fungsional sistem pembuluh perifer bertanggung jawab pada perubahan tekanan darah lansia. Perubahan tersebut meliputi aterosklerosis, hilangnya elastisitas jaringan ikat, dan penurunan relaksasi otot polos pembuluh darah, menurunkan kemampuan distensi dan daya regang pembuluh darah. Kondisi tersebut pada akhirnya mengakibatkan penurunan curah jantung dan peningkatan tahanan perifer (Brunner \& Suddarth's, 2013; Sutanto, 2009; Wolff, 2008; Stanley, Mickey, 2012; Maryam, et al.2008; Tamher, Noorkasiani, 2008).Responden lansia lakilaki maupun perempuan mempunyai faktor risiko hampir sama yaitu faktor usia, tidak adanya pengaturan makanan dan jarang melakukan aktivitas fisik, serta bagi lansia laki-laki mempunyai kebiasan merokok. Hal inil yang menjadikan tidak ada perbedaan pada tekanan sistolik kelompok lansia lakilaki dan perempuan sebelum terapi SEFT.

\section{Perbedaan tekanan sistolik lansia laki-laki dan lansia perempuan sesudah terapi SEFT di Puskesmas Tawang Kota Tasikmalaya}

Hasil penelitian menggambarkan tidak ada perbedaan yang bermakna sesudah dilakukan SEFT. Hal ini terjadi dari faktor usiasehingga organ-organ tubuhnya sudah mengalami penurunan. Dilihat dari sisi psikologis, sebagian besar responden terutama lansia perempuan menyatakan mempunyai permasalahan psikologis selama siklus kehidupannya.Faktor lansia perempuan sudah menopause, ikut memperberat masalah psikologis yang berdampak pada kejadian hipertensi (Raharjo, 2013). Responden laki-laki dan perempuan mempunyai peluang sama dalam penurunan tekanan sistolik setelah
SEFT, karena semua responden mempunyai masalah fisik dan psikologis serta faktor resiko yang menyebabkan hipertensi. Sehingga pada penelitian ini tidak ada perbedaan tekanan sistolik pada lansia lakilaki dan perempuan sesudah terapi SEFT.

Perbedaan tekanan diastolik lansia laki-laki dan lansia perempuan sebelum terapi SEFT di Puskesmas Tawang Kota Tasikmalaya

Pengerasan dan kaku arteri-arteri menjadikan arteri dan aorta kehilangan daya penyesuaian diri.Dinding yang tidak elastis, tidak dapat mengubah darah yang keluar dari jantung menjadi aliran yang lancar (Wolff, 2008; Stanley, Mickey, 2012; Maryam, et al.2008; Tamher, Noorkasiani, 2008). Sebagian besar responden, masih mengkonsumsi makanan dan belum membatasi makanan yang mengandung kadar natrium.Faktor lainnya hampir sebagian besar responden tidak melakukan relaksasi.Semua responden mempunyai faktor risiko, sehingga tekanan darah diastoliknya tidak ada perbedaan pada saat sebelum dilakukan SEFT.

Perbedaan tekanan diastolik lansia lakilaki dan perempuan sesudah terapi SEFT di Puskesmas Tawang Kota Tasikmalaya

Responden lansia perempuan ratarata mempunyai faktor risiko berupa permasalahan psikologis seperti kecemasan yang tinggi dan kegelisahan.Kondisi ini dapat meningkatkan tekanan darah sebesar 30 mmHg (Potter \& Perry, 2009 dalam Oktafiani 2010). Tidak menutup kemungkinan pada responden lansia laki-laki tetapi belum tergali.Faktor risiko lainnya pada lansia lakilaki berupa kebiasaan merokok dan jarang melakukan aktivitas fisik.Ditambah lagi lansia laki-laki tidak mudah menerima sesuatu yang baru sebelum memahaminya.Sehingga efek SEFT pada lansia laki-laki tidak sebaik pada lansia perempuan. 


\section{KESIMPULAN}

Tidak ada perbedaan tekanan sistolik sebelum dan sesudah SEFT pada lansia laki-laki dan perempuan namun ada perbedaan pada tekanan diastolik sesudah terapi SEFT.

\section{SARAN}

Bagi responden yang memiliki faktor risiko sebaiknya dilakukan terapi SEFT pada faktor risikonya terlebih dahulu sebelum melakukan SEFT pada hipertensinya.

\section{DAFTAR PUSTAKA}

Arikunto.(2013). Prosedur Penelitian Suatu Pendekatan Praktek. Jakarta: Rineka Cipta

Badan Penelitian dan Pengembangan Kesehatan Kementrian Kesehatan RI.(2013). Riset Kesehatan Dasar (Riskesdas). Jakarta.

Deby \& Susanti, (2015).Pengaruh Spiritual Emotional Freedom Technique (SEFT) Terhadap Penurunan Tekanan Darah pada Penderita Hipertensi di Wilayah Kerja Puskesmas Kota Pauh Padang. Fakultas Keperawatan

Hidayati, N.R. (2011). Pengaruh Manajemen Cemas: Emotoinal Freedom Technique (EFT) Terhadap Kecemasan Siswa Dalam Menghadapi UAN SMA N 1 Pakem.: Jurnal Sekolah Tinggi IImu Kesehatan Jenderal Achmad Yani Yogyakarta :Yogyakarta.

Maryam, et al. (2008). Mengenal Usia Lanjut dan Perawatannya. Jakarta : Salemba Medika.

Muttaqin.(2009). Asuhan Keperawatan Klien dengan Gangguan Sistem Kardiovaskuler dan Hematologi. Jakarta: Salemba Medika

Pratita \& Oris, (2011).Pengaruh Terapi SEFT (Spiritual Emotional Freedom Technique)terhadap Penurunan Tekanan Darah pada Lansia Hipertensi di Panti Wredha Lawang.Jurnal Universitas Muhammadiyah Lawang

Rofacky.(2015). Pengaruh Terapi Spiritual Emotional Freedom Technique (SEFT) terhadap Tekanan Darah Penderita Hipertensi.Jurnal Keperawatan Soedirman, volume 10, No.1

Stanley, Mickey. (2012). Buku Ajar Keperawatan Gerontik. Jakarta: EGC

Tamher, Noorkasiani. (2012). Kesehatan Usia Lanjut dengan Pendekatan Asuhan Keperawatan. Jakarta : Salemba Medika.

Zainuddin, AF.(2009). Spiritual Emotional Freedom Technique.Jakarta : Afzan Publishing.

.(2014). Spiritual Emotional Freedom Technique (SEFT): Healing, Happiness, Success, Greatness .Jakarta : Afzan Publishing. 